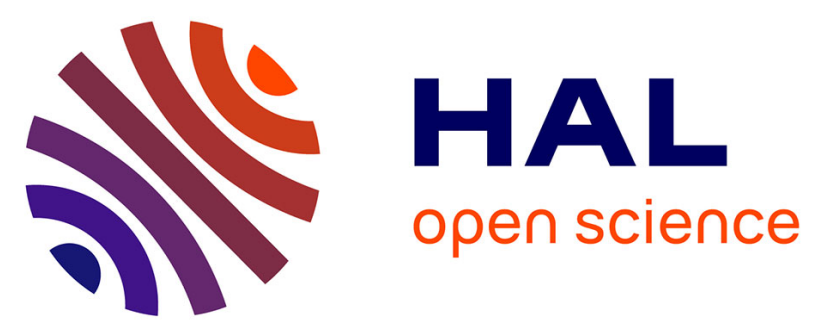

\title{
Altered pattern of Cul-1 protein expression and neddylation in human lung tumors: relationships with CAND1 and cyclin E protein levels
}

Caroline Salon, Elisabeth Brambilla, Christian Brambilla, Sylvie Lantuejoul, Sylvie Gazzeri, Béatrice Eymin

\section{To cite this version:}

Caroline Salon, Elisabeth Brambilla, Christian Brambilla, Sylvie Lantuejoul, Sylvie Gazzeri, et al.. Altered pattern of Cul-1 protein expression and neddylation in human lung tumors: relationships with CAND1 and cyclin E protein levels. Journal of Pathology, 2007, 10.1002/path.2223 . inserm02337643

\section{HAL Id: inserm-02337643 https://www.hal.inserm.fr/inserm-02337643}

Submitted on 29 Oct 2019

HAL is a multi-disciplinary open access archive for the deposit and dissemination of scientific research documents, whether they are published or not. The documents may come from teaching and research institutions in France or abroad, or from public or private research centers.
L'archive ouverte pluridisciplinaire HAL, est destinée au dépôt et à la diffusion de documents scientifiques de niveau recherche, publiés ou non, émanant des établissements d'enseignement et de recherche français ou étrangers, des laboratoires publics ou privés. 


\section{Altered pattern of Cul-1 protein expression and neddylation in human lung tumors: relationships with CAND1 and cyclin E protein levels.}

Caroline Salon $^{1,2}$, Elisabeth Brambilla ${ }^{1,2}$, Christian Brambilla ${ }^{1,2}$, Sylvie Lantuejoul ${ }^{1,2}$, Sylvie

Gazzeri $^{1,2}$ and Beatrice Eymin ${ }^{1,2, *}$.

Equipe Bases Moléculaires de la Progression des Cancers du Poumon, Centre de Recherche

INSERM U823, Institut Albert Bonniot, 38706 La Tronche Cedex

2 Université Joseph Fourier, 38041 Grenoble Cedex 09, France.

Short title: Cul-1 expression in lung tumors.

Accurate word count: 2960 words

* Corresponding author:

Dr. Beatrice Eymin

Centre de Recherche INSERM U823/UJF

Equipe Bases Moléculaires de la Progression des Cancers du Poumon

Institut Albert Bonniot BP170

38042 Grenoble Cedex 09, FRANCE

Tel: +33476549476/ Fax: +33476549413

email: Beatrice.Eymin@ujf-grenoble.fr 


\section{Abstract}

The Cul-1 protein is the scaffold element of SCF complexes that are involved in the proteasomal degradation of numerous proteins regulating cell cycle progression. Owing to this central role in cell growth control, aberrant expression of the components of SCF is supposed to play a role during tumorigenesis. Nothing is known about $\mathrm{Cul}-1$ expression in human tumors. In this study, we have analyzed its status in a series of 128 human lung carcinomas comprising 50 NSCLC (29 squamous cell carcinoma and 21 adenocarcinoma) and 78 neuroendocrine (NE) lung tumors (24 typical and atypical carcinoids, 19 large cell NE carcinoma and 35 small cell lung carcinoma). By using immunohistochemistry, we report for the first time an altered pattern of Cul-1 expression in human tumors. Indeed, we show that Cul-1 expression is upregulated in $40 \%$ (51/128) of all lung tumors as compared to normal lung tissues, including 34\% (17/50), 75\% (18/24) and 30\% (16/54) of NSCLC, carcinoids and high grade neuroendocrine lung carcinoma, respectively. Furthermore, we demonstrate that high levels of Cul-1 protein are associated with a low KI67 proliferative index $(\mathrm{p}=0.005)$ as well as with the decrease of the cyclin $\mathrm{E}$ oncoprotein $(\mathrm{p}=0.0003)$, one of the major target of SCF complexes. These data suggest that upregulation of Cul-1 could protect cells from hyperproliferative signals through cyclin E downregulation. Cul-1 is modified by neddylation, a post-translational modification that grafts ubiquitin-like Nedd8/ Rub1 residues and controls Cul-1 activity. We also provide evidence that neddylated forms of Cul-1 are specifically expressed in high grade NE lung tumors and are associated with a downregulation of the Cul-1 inhibitor CAND1 ( $\mathrm{p}=0.03)$ and a high level of cyclin E $(\mathrm{p}=0.0002)$. These data support the notion that alterations in the Cul-1 neddylation/ deneddylation pathway could contribute to the tumorigenesis of these highly aggressive lung tumors.

Key words: Cul-1, cyclin E, lung tumors, neddylation, Skp2. 


\section{Introduction}

The ubiquitin/proteasome pathway plays an essential and broad role in the stability and activity of many proteins involved in various physiological processes. The conjugation of a polyubiquitin chain on substrates requires the sequential activity of three distinct enzymes: E1, E2 and an ubiquitin-protein ligase, E3, the latter playing an important role in substrate recognition. To date, two major families of E3 ligases have been described, namely the HECT-domain family and the RING family. One of the best-characterized RING E3 ligase is

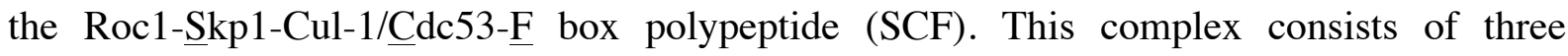
invariable subunits, a Rbx1/Roc1 RING-finger protein, a Skp1 adaptator and a Cul-1 scaffold element, together with a variable component known as the F-box protein that determines the substrate specificity (1). One of the best-characterized F-box protein is Skp2 (S-phase kinaseassociated protein 2), which is the substrate-recognition subunit of the $\mathrm{SCF}^{\mathrm{SKP} 2} \mathrm{E} 3$ ligase complex and a critical binding partner of Cul-1 as such (2). Primary targets of SCF ${ }^{\mathrm{SKP} 2}$ include cell cycle regulators such as $\mathrm{G}_{1}$-phase cyclins, $\mathrm{Cdk}$ inhibitors, DNA replication and transcription factors, as well as non-cell cycle-specific substrates (2). To date, six cul genes have been identified in humans (3). While all of the Cul products are able to bind to Roc1, only Cul-1 interacts with $\operatorname{Skp} 1$ to form the $\operatorname{SCF}$ complex $(4,5)$. Most, if not all, cullin proteins are post-translationally modified by the ubiquitin-like protein Nedd8/Rub1 $(6,7,8$, $\mathrm{Wu}, 2000$ \#67), a phenomenom called neddylation, that is currently thought to enhance the activity of SCF ligases (9).

Bronchogenic carcinoma is the most frequent fatal malignancy in males in Europe and in both sexes in United States. According to the WHO classification of lung cancer (10), lung tumors comprise non small cell lung carcinoma (NSCLC) that include squamous carcinoma, adenocarcinoma and large cell carcinoma, and tumors with neuroendocrine (NE) features that 
are presented in four different entities, small cell lung carcinoma (SCLC), large cell NE carcinoma (LCNEC), a variant of large cell carcinoma, and typical and atypical carcinoids. LCNEC and SCLC can be grouped as high grade neuroendocrine lung cases (HGNE) based on their indistinguishable clinical outcome after stratification per stage (11), their gene expression profiling analysis using cDNA microarrays (12), and their similar patterns of protein expression $(13,14,15,16)$. By contrast, typical and atypical carcinoids are considered as low and intermediate grade NE tumors. Despite the central role of Cul-1 in the proteolytic control of cell-cycle regulators, its status has never been investigated in human tumors. Therefore, the aim of this study was to investigate the expression pattern of the Cul-1 protein in a series of 128 human lung tumors of all histological types, by using immunohistochemistry and immunoblotting. 


\section{Methods}

\section{Tissue samples}

One hundred and twenty eight human lung tumors were included in this study. Tissue samples were taken at surgical resection of lung tumors in 102 cases or at mediastinoscopy of node metastases in 5 cases of Large Cell Neuroendocrine Carcinomas (LCNECs) and 21 cases of Small Cell Lung Carcinomas (SCLCs). Tumor tissues and normal lung parenchyma taken at distance from tumor bulk were immediately frozen and stored at $-80^{\circ} \mathrm{C}$ until use. For histological classification, tumor samples were fixed in formalin and the diagnoses were made on paraffin-embedded material using the current WHO Classification (10). They consisted in 29 squamous cell carcinomas (7 stages I, 6 stages II, 15 stages III and 1 stage IV), 21 adenocarcinomas (14 stages I, 1 stages II, 5 stages III), 14 typical carcinoids (14 stages I) and 10 atypical carcinoids (4 stages I, 4 stages III and 2 stages IV), 19 LCNECs ( 9 stages I, 2 stages II, 7 stages III and 1 stage IV) and 35 SCLCs (1 stage I, 2 stages II, 28 stages III and 2 stages IV). Sixty three patients were suffering from nodal metastasis at the time of diagnosis. We used tumors according to the ethical laws of our country.

\section{Antibodies}

The antibodies used in this study were anti-actin (Sigma, L'Isle d'Abeau), anti-CAND1 (MO1, clone 5D7, Abnova), anti-Cul-1 (Ab1, Neomarkers, Fremont, CA), anti-human Ki67 antigen (DAKO, Glostrup, Denmark), anti-Skp2 (Skp2-2C8D9, Zymed, San Francisco, CA), anti-cyclin E (13A3, Novocastra Newcastle UK) and anti-NEDD8 (Zymed; Alexis). 


\section{Immunohistochemistry (IHC)}

Cul-1 and CAND1 immunostainings were performed on $5 \mu \mathrm{m}$ thick frozen sections that were air-dried and fixed in $10 \%$ paraformaldehyde for 10 minutes at $37^{\circ} \mathrm{C}$ or formalin fixed paraffin-embedded sections, respectively. Endogenous peroxydase activity was inhibited using an $\mathrm{H}_{2} \mathrm{O}_{2}$ solution. Then, a three step immunohistochemical method was applied, with an antigen retrieving step for CAND1. Non specific binding sites were blocked by incubating the sections for 1 hour in donkey normal serum (diluted at 1:50 in phosphatebuffer saline $[\mathrm{PBS}]$ containing $0.03 \%$ bovine serum albumine [BSA]). The sections were subsequently incubated overnight at $4^{\circ} \mathrm{C}$ with the anti-Cul-1 (Ab-1) or anti-CAND1 antibody at 1:300 or 1:500 dilution, respectively. After four ten minutes washes with PBS/0.03\% BSA, the biotinylated donkey anti-rabbit or anti-mouse $\mathrm{F}\left(\mathrm{ab} \mathrm{b}^{\prime}\right) 2$ secondary antibody (1:1000; The Jackson Laboratory, West Grove, PA) was added for 1 hour at room temperature. The detection of bound antibody was accomplished using the streptavidin-biotin-peroxidase complex (1:200; Strept-AB complex; DAKO) for 1 hour at room temperature with diaminobenzidine as a chromogene. The slides were then counterstained with Harris' hematoxylin. Slides incubation with normal rabbit or mouse $\mathrm{IgG}$ at the same concentration as the primary antibody served as a negative control. Immunohistochemical analyses of KI67, Skp2 and cyclin E were carried-out as previously described (16)

\section{Immunohistochemical staining evaluation}

CAND1, Cul-1, Skp2 and cyclin E immunohistochemical analyses were evaluated by two independent observers (CS and EB), in distinct areas of the slide sections for correlation and confirmation of tissues analysis. Immunostaining was scored by taking into account the tumor heterogeneity. A final score (0-300) was established by multiplying the percentage of labeled cells $(0-100 \%)$ with the intensity of staining $(1+, 2+, 3+)$. For Cul-1 and CAND1 
immunodetection analyses, normal bronchi and alveolar epithelial cells were used as internal control (intensity 2+, score 80 to 120 for Cul-1; intensity 2+, score 150 to 200 for CAND1). For Cul-1, as compared to internal controls, tumor samples were graded into two classes according to their score.(class $1: \leq 120$, class 2 : $>120)$. Because Cul-1 protein was clearly detected in normal lung tissues, tumors exhibiting a final score $>120$ (class 2) were considered as cases overexpressing Cul-1. For CAND1, tumors exhibiting a final score $<100$ were considered as tumors having lost CAND1. Skp2 and cyclin E scores were assessed as previously described (16).

\section{Immunoblotting experiments}

Fourty six representative tumoral samples were analyzed and were taken at the immediate vicinity of those studied by immunohistochemistry. Immunoblotting experiments were performed as previously described (14).

\section{Statistical Analyses}

Statistical analysis were performed with a Stat View Program Package (Abacus Concepts, Berkeley, CA, USA). The staining scores were compared through different categories using the Mann-Whitney $U$-Test or Kruskal-Wallis test and correlations were based on the chi-square $\left(X^{2}\right)$ test with a $\mathrm{p}$ value $<0.05$ considered significant. 


\section{Results}

\section{Cul-1 protein expression is altered in human lung carcinoma}

To investigate the Cul-1 protein expression in bronchogenic carcinoma, we first performed immunohistochemical analysis on a panel of 50 NSCLC (21 adenocarcinoma and 29 squamous cell lung carcinoma), 19 LCNEC (Large Cell Neuroendocrine Carcinoma), 35 SCLC (Small Cell Lung Carcinoma) and 24 typical and atypical carcinoids (Table 1 and Figure 1). As Cul-1 immunostaining was heterogeneous among lung tumors, differential scores were ascribed to each case according to the intensity of staining and percentage of stained cells. A mean score was then calculated and tumor samples were grouped in two classes as follow: class 1: no staining or moderate staining, class 2: high staining. Cul-1 was expressed at a moderate level (class 1) in the normal lung parenchyma adjacent to tumor cells on sections, as well as in normal lung epithelium distant from tumor (Figure 1A). As compared to these normal lung tissues, we observed a high level of Cul-1 protein expression in $40 \%(51 / 128)$ of all tumors tested (Table 1). Of the 50 NSCLC analyzed, $34 \%(17 / 50)$ exhibited an upregulation of Cul-1 protein level (Table 1). No significative difference was found between adenocarcinoma and squamous carcinoma. In contrast, Cul-1 was differentially expressed in NE lung tumors. Indeed, carcinoids predominantly overexpressed Cul-1 (75\%, 18/24), whereas 70\% (28/54) of HGNE tumors displayed a low Cul-1 level (Table 1, p $<0.0001$ and Figure 1B). The distinction between atypical carcinoids (AC) and LCNEC is sometimes difficult based on morphological criteria only. Interestingly, the Cul-1 scores were strongly divergent between these two entities (Figure 1C, $\mathrm{p}=0.0002$ ), indicating that Cul-1 IHC status could help to distinguish between AC and LCNEC. Altogether, these results provide the first evidence of an altered pattern of Cul-1 protein expression in human 
lung carcinoma and demonstrate that high levels of Cul-1 are associated with a low grade NE phenotype.

\section{Cul-1 is neddylated in high grade neuroendocrine lung tumors}

To validate our IHC data, we performed western blot analyses in 46 representative tumor samples of the IHC series. Figure 2A illustrates an example of the results. As compared to normal lung tissues in which Cul-1 expression was clearly detected (lanes 1-2 and 9-10), tumor samples exhibited either similar (lanes 14-15), decreased (lanes 4-7, 13) or upregulated (lanes 3, 8, 11-12, 16) Cul-1 expression (Figure 2A). Overall, the immunoblotting results were consistent with those of the IHC study in $80 \%$ of the cases, reflecting a good concordance between both technics (data not shown).

Interestingly, when performing immunoblotting, we repeatedly noticed the appearance of higher migrating forms of Cul-1 in some tumors (Figure 2A, arrows). As these additional bands are reminiscent of neddylated Cul-1 protein $(6,17)$, the immunoblots were repeated using an anti-Nedd8 antibody. As shown in Figure 2A, a neddylated fragment that comigrates at the same electrophoretic size as Cul-1 was detected in the samples with higher Cul-1 migrating bands. Overall, neddylated forms of Cul-1 were detected in 11 of $24(46 \%)$ HGNE lung tumors (Table 2), especially in $\operatorname{SCLC}(9 / 15,60 \%)$ (data not shown). In contrast, neddylation was not observed in normal lung tissues as well as in NSCLC and carcinoids (Figure 2B). Moreover, we did not observe a relationship between the expression level and the neddylated pattern of Cul-1 (Table 2).

The CAND1 protein is an inhibitor of SCF ligases activity that binds unneddylated forms of Cul-1 $(18,19)$. It was previously shown that CAND1 enhances deneddylation of Cul-1 by COP9 signalosome (20). Therefore, we asked whether neddylation of Cul-1 was related to CAND1 status in lung tumors. As shown in figures 3A \& 3B, CAND1 was 
expressed at a moderate level in normal lung tissues, NSCLC and carcinoids. In contrast, it was strongly downregulated in HGNE lung tumors, mostly in SCLC (Figures 3A\&B, $\mathrm{p}<0.0001)$. Importantly, when investigating relationships between CAND1 status and Cul-1 neddylation, we observed an inverse correlation (Figure 3C, p=0.03), suggesting that downregulation of CAND1 contributes to Cul-1 neddylation in HGNE lung tumors.

\section{High levels of Cul-1 correlate with a low KI67 proliferative index and downregulation of Skp2 and cyclin E protein expression in human lung tumors}

To further investigate the role of Cul-1 in human lung carcinogenesis, we studied the relationships between its IHC status and the KI67 proliferative index. As Figure 4 illustrates, a high Cul-1 protein level was associated with a low KI67 index in all tumors tested $(\mathrm{p}=0.005)$. These results suggest that high levels of $\mathrm{Cul}-1$ are predictive of a low proliferative status.

The Skp2 F-box protein is one of the most critical Cul-1 binding protein required for efficient and specific selection of SCF substrates. Interestingly, it was also reported that Cul-1 negatively regulates the expression of Skp2 in cell lines (21). Therefore, our demonstration of an altered pattern of Cul-1 expression in lung tumors led us to investigate the relationships between Cul-1 and Skp2 status. We previously analyzed Skp2 expression by IHC in the same series of lung tumors and showed its overexpression in $32 \%(16 / 50)$ of NSCLC and 59\% (46/78) of NE lung tumors (16). When we integrated the Cul-1 status to these results, we observed that a high level of Cul-1 expression was associated with a low Skp2 score in all tumors $(\mathrm{p}=0.01$, Figure $5 \mathrm{~A})$. Therefore, these results suggest a negative effect of Cul-1 on Skp2 protein expression.

The crucial function of Cul-1 inside SCF complexes is to promote the proteasomal degradation of key regulators of the cell cycle. Thus, we finally wondered whether alteration 
of Cul-1 profile could be associated with a deregulated expression of some of its target genes. The cyclin E oncoprotein is one of the major target of SCF complexes (22). A previous IHC analysis of cyclin $\mathrm{E}$ in our series of tumor samples revealed its elevated expression level in $53 \%(26 / 49)$ and $37 \%(29 / 78)$ of NSCLC and NE lung tumors respectively (16). When investigating the relationships between Cul-1 and cyclin E IHC status, we observed that high levels of Cul-1 strongly correlated with low levels of cyclin $E$ ( $p=0.0003$, Figure 5B). Interestingly, we also found that cyclin $\mathrm{E}$ specifically accumulated in tumors displaying neddylated forms of Cul-1 (Table 3; $\mathrm{p}=0.0002$ ). Overall, these data suggest that both Cul-1 protein level and neddylation pattern might be involved in the control of cyclin E status in lung tumors. 


\section{Discussion}

Cul-1 is the scaffold component of SCF (Skp1-Cul-1-F-box protein) complexes that control the proteolysis of a large number of proteins predominantly involved in cell cycle progression (23, for review). Numerous studies have already reported the abnormal expression of F-box proteins in human cancers. In contrast, and despite its core position inside SCF complexes, the Cul-1 status remains largely unknown in human malignancies. In this study, we provide the first evidence of an altered pattern of Cul-1 expression in human lung carcinoma with $40 \%$ of tumors displaying high levels as compared to normal lung. Controversial data exist as regard to the role played by Cul-1 in cellular growth control. Some studies have suggested that Cul-1 positively regulates cell cycle progression $(24,25,26)$. In contrast, other reports implicate Cul-1 as an inhibitor of the cell cycle. Indeed, Cul-1 loss-offunction mutations in C. elegans lead to hyperplasia with a shortened G1 phase of the cell cycle (3). In this study, we demonstrate that high Cul-1 protein levels correlate with a low KI67 proliferative index, suggesting that upregulation of Cul-1 could counteract hyperproliferative signals generated in tumor cells. Furthermore, as inactivation of Cul-1 functions leads to genetic instability and neoplastic transformation in mice $(27,28)$, our results suggest that high levels of Cul-1 might also protect cells from genetic instability. This could explain why the majority of carcinoids (75\%) which are characterized by low proliferative index and low genetic instability, display high levels of Cul-1.

Most, if not all cullin proteins are post-translationally modified by the ubiquitin-like protein Nedd8/Rub1 (6, 7, 8, Wu, 2000 \#67). By using immunoblotting, we observed that neddylated forms of Cul-1 accumulate in HGNE lung tumors whereas we were unable to detect Cul-1 neddylation in NSCLC and carcinoids as well as in normal lung tissues. Neddylation was recently reported to control the stability of the Cul-1 protein (29) but we did 
not observe a correlation between Cul-1 neddylation and total expression level in NE lung tumors. In contrast, we found that the Cul-1 inhibitor CAND1 is strongly downregulated in HGNE lung carcinoma as compared to normal lung tissues, carcinoids and NSCLC. Moreover, we also show that CAND1 protein level is inversely related with expression of neddylated forms of Cul-1 (Figure 3C, $\mathrm{p}=0.03$ ). Altogether, these results suggest that a low level of CAND1 could contribute to the maintenance of neddylated Cul-1 in HGNE lung tumors. The conjugation of Nedd8 to the arginine residue at position 720 of Cul-1 is currently thought to enhance the activity of SCF ligases, likely by increasing their affinity for some E2 enzymes (9). However, it has also been reported that accumulation of hyperneddylated Cul-1 correlates with a decreased rather than an enhanced SCF activity $(18,30,31)$. In this study, we provide evidence that neddylation of Cul-1 is associated with high levels of the cyclin E protein $(\mathrm{p}=0.0002)$, one of the major target of SCF complexes. These data suggest that accumulation of neddylated forms of Cul-1 in HGNE lung tumors could inactivate rather than activate SCF complexes. It was recently demonstrated that supplementation of cellular extracts with substrate could prevent the deneddylation of cullins (32). Therefore, we cannot exclude that high levels of cyclin E could cooperate with CAND1 downregulation for the maintenance of neddylated Cul-1 in HGNE lung tumors.

Knock-out mice models have previously shown that both Cul-1 and Cul-3 proteins negatively control cyclin E protein level $(26,27,33)$. Here, we show that high Cul-1 levels correlate with a decrease of cyclin E protein in lung tumors ( $\mathrm{p}=0.0003$, Figure $5 \mathrm{~B}$ ). These data are in favor of cyclin E being an important target of Cul-1 in these tumors. Such effect was not linked to a general activation of SCF complexes, since we did not found a correlation between Cul-1 and p27 ${ }^{\mathrm{Kip} 1}$, another major target of SCF (data not shown). Therefore, as Cul-1 neddylation was unrelated to its total expression level in this study, both phenomena could contribute to the regulation of cyclin E expression, at least in HGNE lung tumors. So 
SCF complexes, namely $\mathrm{SCF}^{\mathrm{SKP} 2}$ and $\mathrm{SCF}^{\mathrm{FBW} 7}$, have been involved in the proteasomal degradation of cyclin E (23). Since accumulation of Cul-1 strongly correlates with low levels of the Skp2 F-box protein in lung tumors ( $\mathrm{p}=0.0117$, Figure 4A), it is tempting to speculate that $\mathrm{SCF}^{\mathrm{FBW} 7}$ complexes could play a role in cyclin $\mathrm{E}$ downregulation. Interestingly, a predominant role of FBW7 in regulating cyclin E turnover was recently reported (34). It remains to be determined whether the status of FBW7 is altered and correlates with that of Cul-1 in human lung tumors.

\section{Aknowledgements}

We thank Patricia Betton, Pascal Perron, Christine Claraz and Sylvie Veyrenc for technical assistance. This work was supported by grants from the Region Rhône Alpes (Thématique Prioritaire Cancer and Canceropole 2003: Oncocell, Epimed and INACancer), by the Ligue Nationale contre le Cancer as an Equipe Labellisée, by the Conseil Scientifique National d'AGIR a dom and by INCa (Programme National d'Excellence Spécialisé 2005). CS was supported by a "poste accueil” INSERM. 


\section{References}

1. Zheng N, Schulman BA, Song L, Miller JJ, Jeffrey PD, Wang P, et al. Structure of the Cul1-Rbx1-Skp1-F boxSkp2 SCF ubiquitin ligase complex. Nature 2002;416(6882):703-9.

2. Kipreos ET, Pagano M. The F-box protein family. Genome Biol 2000;1(5):REVIEWS3002.

3. Kipreos ET, Lander LE, Wing JP, He WW, Hedgecock EM. cul-1 is required for cell cycle exit in C. elegans and identifies a novel gene family. Cell 1996;85(6):829-39.

4. Lyapina SA, Correll CC, Kipreos ET, Deshaies RJ. Human CUL1 forms an evolutionarily conserved ubiquitin ligase complex (SCF) with SKP1 and an F-box protein. Proc Natl Acad Sci U S A 1998;95(13):7451-6.

5. Michel JJ, Xiong Y. Human CUL-1, but not other cullin family members, selectively interacts with SKP1 to form a complex with SKP2 and cyclin A. Cell Growth Differ $1998 ; 9(6): 435-49$.

6. Furukawa M, Zhang Y, McCarville J, Ohta T, Xiong Y. The CUL1 C-terminal sequence and ROC1 are required for efficient nuclear accumulation, NEDD8 modification, and ubiquitin ligase activity of CUL1. Mol Cell Biol 2000;20(21):8185-97.

7. Podust VN, Brownell JE, Gladysheva TB, Luo RS, Wang C, Coggins MB, et al. A Nedd8 conjugation pathway is essential for proteolytic targeting of p27Kip1 by ubiquitination. Proc Natl Acad Sci U S A 2000;97(9):4579-84.

8. Read MA, Brownell JE, Gladysheva TB, Hottelet M, Parent LA, Coggins MB, et al. Nedd8 modification of cul-1 activates $\mathrm{SCF}($ beta(TrCP))-dependent ubiquitination of IkappaBalpha. Mol Cell Biol 2000;20(7):2326-33.

9. Kawakami T, Chiba T, Suzuki T, Iwai K, Yamanaka K, Minato N, et al. NEDD8 recruits E2-ubiquitin to SCF E3 ligase. Embo J 2001;20(15):4003-12. 
10. Travis WD, Colby TV, Corrin B, Shimosato Y, Brambilla E. WHO international Histological Classification of Tumours: Histological Typing of Lung and Pleural Tumours. Ed Springer 1999; Third Edition.

11. Travis WD, Rush W, Flieder DB, Falk R, Fleming MV, Gal AA, et al. Survival analysis of 200 pulmonary neuroendocrine tumors with clarification of criteria for atypical carcinoid and its separation from typical carcinoid. Am J Surg Pathol 1998;22(8):934-44.

12. Jones MH, Virtanen C, Honjoh D, Miyoshi T, Satoh Y, Okumura S, et al. Two prognostically significant subtypes of high-grade lung neuroendocrine tumours independent of small-cell and large-cell neuroendocrine carcinomas identified by gene expression profiles. Lancet 2004;363(9411):775-81.

13. Gazzeri S, Della Valle V, Chaussade L, Brambilla C, Larsen CJ, Brambilla E. The human p19ARF protein encoded by the beta transcript of the p16INK4a gene is frequently lost in small cell lung cancer. Cancer Res 1998;58(17):3926-31.

14. Eymin B, Gazzeri S, Brambilla C, Brambilla E. Distinct pattern of E2F1 expression in human lung tumours: E2F1 is upregulated in small cell lung carcinoma. Oncogene 2001;20(14):1678-87.

15. Viard-Leveugle I, Veyrenc S, French LE, Brambilla C, Brambilla E. Frequent loss of Fas expression and function in human lung tumours with overexpression of FasL in small cell lung carcinoma. J Pathol 2003;201(2):268-77.

16. Salon C, Merdzhanova G, Brambilla C, Brambilla E, Gazzeri S, Eymin B. E2F-1, Skp2 and cyclin E oncoproteins are upregulated and directly correlated in high-grade neuroendocrine lung tumors. Oncogene 2007.

17. Wu K, Chen A, Pan ZQ. Conjugation of Nedd8 to CUL1 enhances the ability of the ROC1-CUL1 complex to promote ubiquitin polymerization. J Biol Chem 2000;275(41):32317-24. 
18. Liu J, Furukawa M, Matsumoto T, Xiong Y. NEDD8 modification of CUL1 dissociates p120(CAND1), an inhibitor of CUL1-SKP1 binding and SCF ligases. Mol Cell 2002;10(6):1511-8.

19. Goldenberg SJ, Cascio TC, Shumway SD, Garbutt KC, Liu J, Xiong Y, et al. Structure of the Cand1-Cul1-Roc1 complex reveals regulatory mechanisms for the assembly of the multisubunit cullin-dependent ubiquitin ligases. Cell 2004;119(4):517-28.

20. Min KW, Kwon MJ, Park HS, Park Y, Yoon SK, Yoon JB. CAND1 enhances deneddylation of CUL1 by COP9 signalosome. Biochem Biophys Res Commun 2005;334(3):867-74.

21. Wirbelauer C, Sutterluty H, Blondel M, Gstaiger M, Peter M, Reymond F, et al. The F-box protein Skp2 is a ubiquitylation target of a Cul1-based core ubiquitin ligase complex: evidence for a role of Cul1 in the suppression of Skp2 expression in quiescent fibroblasts. Embo J 2000;19(20):5362-75.

22. Nakayama K, Nagahama H, Minamishima YA, Matsumoto M, Nakamichi I, Kitagawa $\mathrm{K}$, et al. Targeted disruption of Skp2 results in accumulation of cyclin E and p27(Kip1), polyploidy and centrosome overduplication. Embo J 2000;19(9):2069-81.

23. Nakayama KI, Nakayama K. Ubiquitin ligases: cell-cycle control and cancer. Nat Rev Cancer 2006;6(5):369-81.

24. Feldman RM, Correll CC, Kaplan KB, Deshaies RJ. A complex of Cdc4p, Skp1p, and Cdc53p/cullin catalyzes ubiquitination of the phosphorylated CDK inhibitor Sic1p. Cell 1997;91(2):221-30.

25. Patton EE, Willems AR, Sa D, Kuras L, Thomas D, Craig KL, et al. Cdc53 is a scaffold protein for multiple Cdc34/Skp1/F-box proteincomplexes that regulate cell division and methionine biosynthesis in yeast. Genes Dev 1998;12(5):692-705. 
26. Wang Y, Penfold S, Tang X, Hattori N, Riley P, Harper JW, et al. Deletion of the Cul1 gene in mice causes arrest in early embryogenesis and accumulation of cyclin E. Curr Biol 1999;9(20):1191-4.

27. Dealy MJ, Nguyen KV, Lo J, Gstaiger M, Krek W, Elson D, et al. Loss of Cul1 results in early embryonic lethality and dysregulation of cyclin E. Nat Genet 1999;23(2):245-8.

28. Piva R, Liu J, Chiarle R, Podda A, Pagano M, Inghirami G. In vivo interference with Skp1 function leads to genetic instability and neoplastic transformation. Mol Cell Biol 2002;22(23):8375-87.

29. Wu JT, Lin HC, Hu YC, Chien CT. Neddylation and deneddylation regulate Cull and Cul3 protein accumulation. Nat Cell Biol 2005;7(10):1014-20.

30. Ohh M, Kim WY, Moslehi JJ, Chen Y, Chau V, Read MA, et al. An intact NEDD8 pathway is required for Cullin-dependent ubiquitylation in mammalian cells. EMBO Rep 2002;3(2):177-82.

31. Denti S, Fernandez Sanchez ME, Rogge L, Bianchi E. The COP9 signalosome regulates Skp2 levels and proliferation of human cells. J Biol Chem 2006.

32. Bornstein G, Ganoth D, Hershko A. Regulation of neddylation and deneddylation of cullin1 in SCFSkp2 ubiquitin ligase by F-box protein and substrate. Proc Natl Acad Sci U S A 2006;103(31):11515-20.

33. Singer JD, Gurian-West M, Clurman B, Roberts JM. Cullin-3 targets cyclin E for ubiquitination and controls S phase in mammalian cells. Genes Dev 1999;13(18):2375-87.

34. Zhang W, Koepp DM. Fbw7 isoform interaction contributes to cyclin E proteolysis. Mol Cancer Res 2006;4(12):935-43. 
Table 1. Immunohistochemical analysis of Cul1 protein expression in human lung carcinoma according to histological sub-types.

\section{Cul-1 expression level}

\begin{tabular}{|c|c|c|c|c|}
\hline Histological sub-type & $\mathrm{nb}$ & class $1^{a}$ & class $2^{a}$ & $p^{e}$ \\
\hline Adenocarcinoma & 21 & $13(62 \%)$ & $8(38 \%)$ & \\
\hline Squamous carcinoma & 29 & $20(69 \%)$ & $9(31 \%)$ & NS \\
\hline Total NSCLC ${ }^{\text {b }}$ & 50 & $33(66 \%)$ & $17(34 \%)$ & \\
\hline Carcinoids & 24 & $6(25 \%)$ & $18(75 \%)$ & $<00001$ \\
\hline $\begin{array}{l}\text { LCNEC }^{\mathrm{c}} \\
\text { Small Cell Carcinoma } \\
\text { Total HGNE } \text { carcinoma }^{\mathbf{d}}\end{array}$ & $\begin{array}{l}19 \\
35\end{array}$ & $\begin{array}{l}12(63 \%) \\
25(72 \%)\end{array}$ & $\begin{array}{c}7(37 \%) \\
10(28 \%)\end{array}$ & \\
\hline Total tumors & 128 & $77(60 \%)$ & $51(40 \%)$ & 0.0009 \\
\hline
\end{tabular}

Immunostaining scores were calculated by multiplying the number of labeled cells $(0$ to $100 \%$ ) by the level of intensity ( 1 to 3 ). According to this, the samples were grouped in two classes as described in the material and methods section and as follow ${ }^{\text {a }}$ class 1: low level of Cul1 protein expression (score $\leq 120$ ), class 2: high level of Cul1 protein expression (score $>120$ ). nb: number of cases in each histological type. ${ }^{b}$ Non small cell lung carcinoma. ${ }^{c}$ Large cell neuroendocrine carcinoma. ${ }^{\mathrm{d}}$ High grade neuroendocrine lung tumors. ${ }^{\mathrm{e}} \chi 2$ test. NS, non significant. 
Table 2. Relationships between Cul-1 protein level and its neddylated status in human lung carcinomas.

\begin{tabular}{|c|c|c|c|c|c|c|}
\hline \multirow{2}{*}{$\begin{array}{c}\text { Histological } \\
\text { types }\end{array}$} & \multirow{2}{*}{$n b$} & \multicolumn{2}{|c|}{ Class $1^{a}$} & \multicolumn{2}{|c|}{ Class $2^{b}$} & \multirow[t]{2}{*}{$P^{e}$} \\
\hline & & Nedd $8+{ }^{c}$ & Nedd $8-^{d}$ & $\operatorname{Nedd} 8+^{c}$ & Nedd $8-^{d}$ & \\
\hline NSCLC & 15 & 0 & 11 & 0 & 4 & $N S$ \\
\hline Carcinoids & 7 & 0 & 1 & 0 & 6 & $N S$ \\
\hline$H G N E$ & 24 & 4 & 10 & 7 & 3 & $N S$ \\
\hline tumors Total & 46 & 4 & 22 & 7 & 13 & $N S$ \\
\hline
\end{tabular}

${ }^{a, b}$ Tumors displaying a low ${ }^{a}$ or high ${ }^{b}$ Cul-1 protein level as detected by immunoblotting using an anti-cullin-1 antibody. ${ }^{c}$ Nedd $8+$ : Tumor samples with neddylated Cul-1 as detected by immunoblotting using an anti-Nedd8 antibody. ${ }^{d}$ Nedd 8 - : Tumor samples without neddylated Cul-1 as detected by immunoblotting. ${ }^{e} \chi^{2}$ test. nb: number of tumoral samples. NS : non significant. 
Table 3. Relationships between Cul-1 neddylation and cyclin E protein level in HGNE lung carcinomas.

\begin{tabular}{lccc}
\hline & Nedd $8-^{\mathrm{c}}$ & Nedd $8+{ }^{\mathrm{d}}$ & $\mathrm{P}^{\mathrm{e}}$ \\
\cline { 2 - 3 } Cyclin E low level $^{\mathrm{a}}$ & 8 & 0 & \\
Cyclin E high level $^{\mathrm{b}}$ & 1 & 8 & 0.0002 \\
\hline
\end{tabular}

${ }^{\mathrm{a}}$ Tumors displaying a score of cyclin $\mathrm{E}<40 .{ }^{\mathrm{b}}$ Tumors displaying a score of cyclin $\mathrm{E} \geq 40$ and considered as overexpressing cases. ${ }^{\mathrm{c}, \mathrm{d}}$ Nedd 8 -: tumor samples without neddylated Cul-1 as detected by immunoblotting using an anti-Nedd 8 antibody ; Nedd $8+$ : tumor samples with neddylated Cul-1. ${ }^{\mathrm{e}} \chi 2$ test. HGNE: High Grade Neuroendocrine Lung tumors. 


\section{Legends}

Figure 1. (A) Cul-1 immunostaining of normal lung parenchyma and lung cancer tissues on frozen sections using an anti-Cul-1 rabbit polyclonal antibody (Neomarkers). Moderate staining in (a) bronchiolar or (b) alveolar normal epithelium. (c) Strong Cul-1 immunostaining in a typical carcinoid. (d). Cul-1 loss in a small cell lung carcinoma. (e) Moderate and (f) strong Cul-1 immunostaining in two squamous cell carcinoma. (B) Cul-1 scores in carcinoids, HGNE lung carcinoma and NSCLC. (C) Comparison of Cul-1 scores between atypical carcinoids and LCNEC. Statistical analyses were performed using a MannWhitney $U$-test. NS: not significant.

Figure 2. (A) Cul-1 expression was analyzed by immunoblotting in normal (N) and tumoral (T) lung samples. Cul-1 expression was upregulated (T3, T8, T11-12, T16) or downregulated (T4-7, T13) according to the samples. T14-15 expressed similar levels of Cul-1 as normal lung. Arrows in the upper blot represent higher migrating forms of neddylated Cul-1 protein. Neddylation was confirmed by using an anti-Nedd8 antibody. Actin was used as a loading control. (B) Cul-1 expression and neddylation in 7 lung carcinoids were analyzed as described in $(\mathrm{A})$.

Figure 3. (A) CAND1 immunostaining of normal lung parenchyma and lung cancer tissues on paraffin-embedded sections using an anti-CAND1 mouse monoclonal antibody (5D7, Abnova). (a) Moderate staining in bronchiolar normal epithelium. (b) Strong CAND-1 immunostaining in a squamous cell carcinoma. (c) CAND-1 loss in a small cell lung carcinoma. (d) Moderate CAND-1 immunostaining in a typical carcinoid (only nuclear reactivity was assessed). (B) Comparison of CAND1 scores between carcinoids, HGNE 
carcinoma and NSCLC. Statistical analyses were performed using a Kruskal-Wallis test. (C) CAND1 scores according to the presence (NEDD8 +) or absence (NEDD8 -) of Cul-1 neddylation. Statistical analyses were performed using a Mann-Whitney $U$-test.

Figure 4. Percentage of tumoral cells positive for KI67 immunostaining in lung tumors according to high (white box) or low (black hatched box) Cul-1 protein levels. Statistical analyses were performed using a Mann-Whitney $U$-test. NS: not significant.

Figure 5: Skp2 (A) and cyclin E (B) protein scores in lung tumors according to high (white box) or low (black hatched box) Cul-1 protein levels. Statistical analyses were performed using a Mann-Whitney $U$-test. NS: not significant. 